\title{
Fabrication and characterization of hydroxyapatite-coated forsterite scaffold for tissue regeneration applications
}

\author{
ROYA SAIDI ${ }^{1, *}$, MOHAMMAD HOSSEIN FATHI ${ }^{1,2}$ and HAMIDREZA SALIMIJAZI ${ }^{3}$ \\ ${ }^{1}$ Biomaterials Research Group, Department of Materials Engineering, Isfahan University of Technology, \\ Isfahan 8415683111, Iran \\ ${ }^{2}$ Dental Materials Research Center, Isfahan University of Medical Sciences, Isfahan 8174673461, Iran \\ ${ }^{3}$ Department of Materials Engineering, Isfahan University of Technology, Isfahan 8415683111, Iran
}

MS received 19 April 2015; accepted 8 May 2015

\begin{abstract}
In this study, a novel hydroxyapatite (HA)-coated forsterite scaffold with a desired porous structure, high mechanical properties and good bioactivity was successfully fabricated via gel-casting and sol-gel in low pressure methods. X-ray diffraction, scanning electron microscopy, transmission electron microscopy and $X$-ray map techniques were utilized in order to evaluate the phase composition, dimension, morphology, interconnectivity of the pores and state of the coating on the porosities of the synthesized scaffold. The porosity and compressive strength of the scaffolds were measured and the bioactivity was investigated by soaking the scaffolds in simulated body fluid (SBF). The results show that the prepared scaffolds had highly interconnected spherical pores with size in the range of $65-245 \mu \mathrm{m}$. Additionally, compressive strength and elastic modulus were $7.5 \pm 0.2$ and $291 \pm 10 \mathrm{MPa}$, respectively. The crystallite size of the scaffolds was less than $60 \mathrm{~nm}$. True (total) and apparent (interconnected) porosity of the scaffolds were in the range of $75-80$ and $65-70 \%$, respectively. In vitro tests in the SBF also confirmed good bioactivity of the prepared scaffolds. While bone-like apatite formation started from the first day of soaking and apatite covered the entire surface and inner wall of the scaffolds pores at long immersion time. Conclusion suggested that HA coating on forsterite scaffolds could significantly improve the mechanical properties and bioactivity, which might be promising for tissue engineering applications.
\end{abstract}

Keywords. Ceramics; mechanical alloying; gelcasting process; porosity; mechanical properties.

\section{Introduction}

Bioactive materials with different properties are used for bone repair and bone tissue engineering applications. ${ }^{1}$ Easy production and good biocompatibility of bioceramics make them the most important group of biomaterials. $^{2,3}$ Nowadays much attention is paid to porous bioceramics, foams or scaffolds. ${ }^{4}$ An ideal scaffold intends to mimic the mechanical and biochemical properties of the native tissue. ${ }^{5}$

Hydroxyapatite (HA) is the most widely used bioscaffolds in hard tissue repair due to its chemical and crystallographic resemblance to the mineral component of human bone and teeth. It also has excellent biocompatibility, bioactivity, osteoconduction and osteointegration properties. $^{6-9}$ However, its brittleness and weak mechanical properties such as low fracture toughness restrict its use in load-bearing applications. , $^{3,10,11}$ To be used effectively in such applications, the mechanical properties of

\footnotetext{
*Author for correspondence (r.saidighahe@ma.iut.ac.ir)
}

HA need to be improved. ${ }^{12}$ The incorporation of other ceramics with better mechanical properties such as forsterite $\left(\mathrm{Mg}_{2} \mathrm{SiO}_{4}\right)$ might improve the mechanical properties of HA. ${ }^{13}$

Forsterite is a crystalline magnesium silicate, which belongs to the group of olivine. ${ }^{8,14-16}$ In recent years, forsterite has gained popularity due to its wide range of applications. This bioceramic is a biocompatible material with high mechanical properties. ${ }^{2,4,10,16-19}$ Comparison to calcium phosphate ceramics such as HA $(\mathrm{KIC}=0.75-$ 1.2 $\mathrm{MPa} \mathrm{m}^{1 / 2}$ ), forsterite ceramics showed a significant improvement in the fracture toughness $\left(\mathrm{KIC}=2.4 \mathrm{MPam}^{1 / 2}\right.$ ) and were superior to the lower limit reported for cortical bone. This makes forsterite as a possible candidate for load-bearing applications. ${ }^{3,20-22}$

Ghomi et $a l^{4}$ fabricated forsterite scaffold via the gel-casting method. The scaffold had compressive strength of about $2.5 \mathrm{MPa}$, which is not good enough for load-bearing applications.

The aim of this work was to develop a new route to enhance the compressive strength of forsterite scaffold via two-step sintering process of forsterite scaffolds and coating with HA. 


\section{Experimental}

\subsection{Synthesis of nanostructured forsterite powder}

A mixture of magnesium hydroxide carbonate $\left(4 \mathrm{MgCO}_{3}\right.$. $\mathrm{Mg}(\mathrm{OH})_{2} \cdot 5 \mathrm{H}_{2} \mathrm{O}$, Merck) and silicon dioxide $\left(\mathrm{SiO}_{2}\right.$, Merck) was mechanically activated using a high-energy planetary ball mill for $10 \mathrm{~h}$ under ambient condition. Zirconia vial and five zirconia balls with a diameter of $20 \mathrm{~mm}$ were utilized as milling media. Mechanical activation was performed using ball/powder mass ratio of $12.5: 1$ and rotation speed of $250 \mathrm{rpm}$. The prepared powder was then heated at $900^{\circ} \mathrm{C}$ for $1 \mathrm{~h}$ in air atmosphere and isothermal condition.

\subsection{Fabrication of forsterite scaffold}

Forsterite scaffold was prepared by the gel-casting method; an effective process for the fabrication of highly porous ceramics. ${ }^{23}$ For this purpose, forsterite powder was added to a solution of $1 \mathrm{wt} \%$ tripolyphosphate sodium as a dispersant in deionized water to make a suspension of $45 \mathrm{wt} \%$ solid loading. Coincidently, agarose (a gelling agent) solution in deionized water (7 wt \%) was warmed up to $80^{\circ} \mathrm{C}$. Later, the agarose solution was added to the forsterite slurry by keeping the temperature of the initial slurry at $80^{\circ} \mathrm{C}$ to obtain a forsterite suspension. Finally, tergitol as a surfactant was added to the prepared suspension. Foaming was conducted through agitation with the help of a triple-blade mixer at $80^{\circ} \mathrm{C} .{ }^{4}$ The prepared slurry was poured into the glass molds and cooled to $0^{\circ} \mathrm{C}$. The green bodies were then left at room conditions to dry and sintered via two-step sintering process similar to previous reports. The flowchart of two-step sintering process is shown in figure 1.

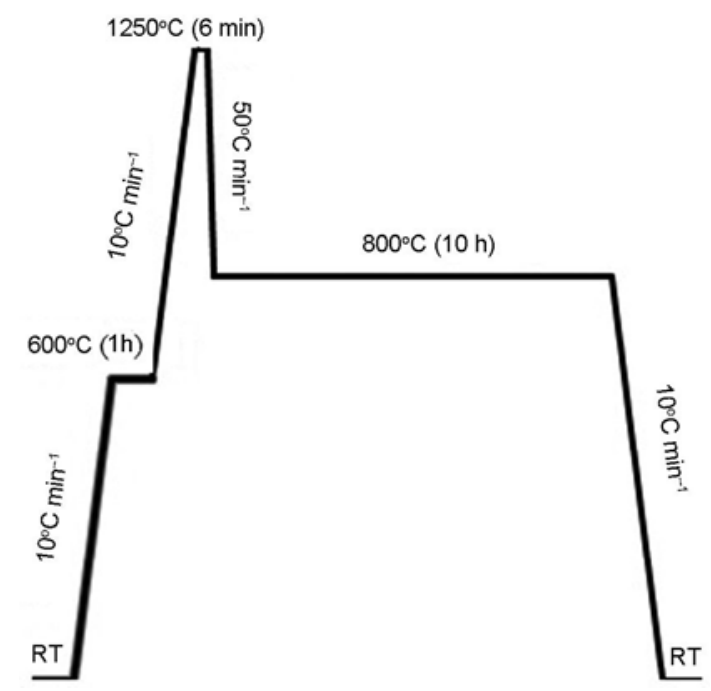

Figure 1. Detailed flowchart of two-step sintering of forsterite scaffold.

\subsection{Preparation of HA coating sol}

A certain amount of phosphoric pentoxide $\left(\mathrm{P}_{2} \mathrm{O}_{5}\right.$, Merck $)$ was dissolved in perfect ethanol to produce a $0.5 \mathrm{~mol} \mathrm{l}^{-1}$ solution. At the same time, a designed amount of calcium nitrate tetrahydrate $\left(\mathrm{Ca}\left(\mathrm{NO}_{3}\right)_{2} \cdot 4 \mathrm{H}_{2} \mathrm{O}\right.$, Merck) was also dissolved in absolute ethanol to form a $1.67 \mathrm{~mol} \mathrm{l}^{-1}$ solution in another beaker. The solutions were mixed with a molar ratio of $\mathrm{Ca} / \mathrm{P}=1.67$ and the initial mixture was prepared. $^{24-26}$ The mixture was continuously stirred for $3 \mathrm{~h}$ at ambient temperature to obtain a white transparent gel. After preparing the gel, the forsterite scaffolds were coated via the method mentioned in section 2.3a. After $24 \mathrm{~h}$ aging in the ambient temperature, the samples were dried at $80^{\circ} \mathrm{C}$ for $24 \mathrm{~h}$ in an electrical air oven. Finally, the samples were sintered at $600^{\circ} \mathrm{C}$ for $1 \mathrm{~h}$ in a resistance furnace with a heating rate of $5^{\circ} \mathrm{C} \min ^{-1} \cdot{ }^{24-26}$

2.3a Coating forsterite scaffold: As the forsterite scaffold was porous and air is present in the pores, the solgel method at low pressure was chosen. This technique provides quick and comfortable coatings of sol, leading to the creation of a uniform coverage. Forsterite scaffold was placed in the beaker inside the desiccator and the inner pressure was set to -0.8 Torr relative to the ambient pressure. When the inner pressure of the desiccator reached the mentioned amount, the hoses connecting the desiccator to the beaker containing the coating sol was opened, and the coating sol entered the beaker inside the desiccator. When the sol encompassed the scaffold, the vacuum was disconnected and the scaffold was excluded.

\subsection{Materials characterization}

Phase structure characterization of forsterite powder, scaffolds and HA coating were performed using the X-ray diffractometer (XRD) (Philips X'Pert-MPD, $\mathrm{CuK} \alpha$ radiation $=0.154 \mathrm{~nm}, 2 \theta$ range of $20-80^{\circ}$, step size: $0.05^{\circ}$ and time per step: $1 \mathrm{~s}$ ).

The crystallite size of forsterite powder and the prepared scaffolds were determined using broadening of XRD pattern peaks and Scherrer's equation ${ }^{27}$

$$
d=\frac{0.89 \lambda}{B \cos \theta},
$$

where $d$ is the crystallite size (nm), $\lambda$ the wavelength $(\lambda=0.154 \mathrm{~nm}), B$ the broadening of diffraction line measured at half its maximum intensity and $\theta$ the Bragg angle (deg).

The surface morphology of the scaffolds was studied by field-emission scanning electron microscopy (SEM) (Philips XL30 FEG) coupled with energy-dispersive spectrometer. X-ray map was utilized to evaluate the formation of HA coating on the surface of forsterite scaffold porosities. 
Transmission electron microscopy (TEM, Philips GM120FEG) was used to study the morphology and particle size of the prepared scaffold.

The porosity of scaffolds was measured according to the Archimedes principle with distilled water as an immersion medium and by using the theoretical density of $3.221 \mathrm{~g} \mathrm{~cm}^{-3}$ for forsterite. ${ }^{28}$

In order to determine the mechanical properties of the samples, compressive tests were performed using a compression test machine (Hounsfield, H25KS). For this purpose, the samples were cubed with dimensions $5 \times 10 \times$ $10 \mathrm{~mm}^{3}$ and the crosshead speed of $0.5 \mathrm{~mm} \mathrm{~min}^{-1}$ was utilized. $^{12,29}$

The compressive strength of each scaffold was calculated as the maximum applied force divided by the measured initial bulk cross-sectional area of the specimen, and the elastic modulus was calculated as the slope of the initial linear portion of the stress-strain curve. The final result was presented as the average of three measurements and the standard deviation for HA-coated forsterite scaffold. The bioactivity of the scaffolds was determined in vitro through the immersion of prepared samples in SBF as described by Bohner and Lemaitre ${ }^{30}$ at $36.5 \pm$ $0.5^{\circ} \mathrm{C}$ for 28 days. As-prepared scaffolds were placed in sterilized bottles with a solid/liquid ratio of $10 \mathrm{mg} \mathrm{ml}^{-1}$. The samples were then filtered, rinsed with distilled water and dried in air. The formation of apatite-like layer on the samples was investigated and studied by SEM. In addition, the SBF solution was also monitored for the changes of $\mathrm{pH}$ using an electrolyte-type $\mathrm{pH}$ meter (Netrohm827), and variations in $\mathrm{Ca}$ and $\mathrm{P}$ ions were evaluated via using inductively coupled plasma optical emission spectrometry (ICP-OES, Perkin Elmer).

\section{Results and discussion}

Figure 2 shows the XRD patterns of the prepared forsterite powder and forsterite scaffold. It is obvious that only the forsterite peaks existed in the pattern (JCPD

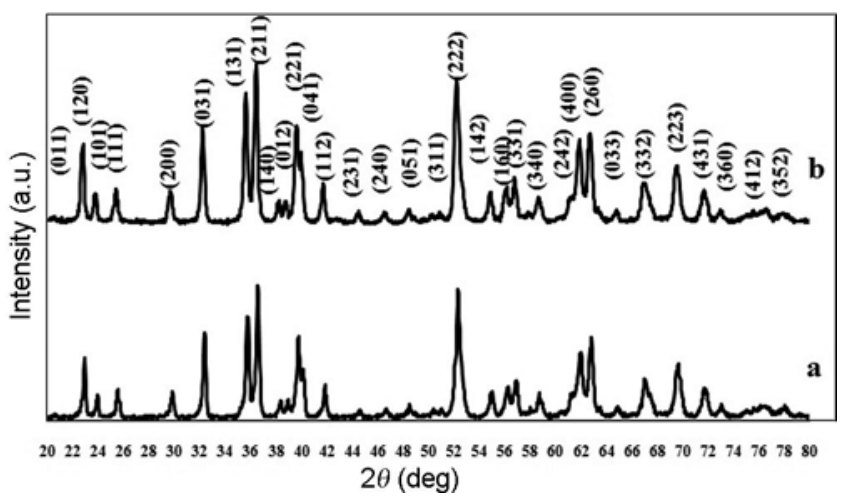

Figure 2. XRD patterns of prepared (a) forsterite nanopowder and (b) forsterite scaffold.
34-0189), indicating successful preparation of a pure forsterite powder and forsterite scaffold. The crystallite size of the forsterite scaffolds was in the range of 35-60 $\mathrm{nm}$ by broadening of XRD peaks using Scherrer's formula.

Figure 3 shows TEM micrographs of forsterite scaffold. TEM micrographs show that the particle size is smaller than $150 \mathrm{~nm}$.
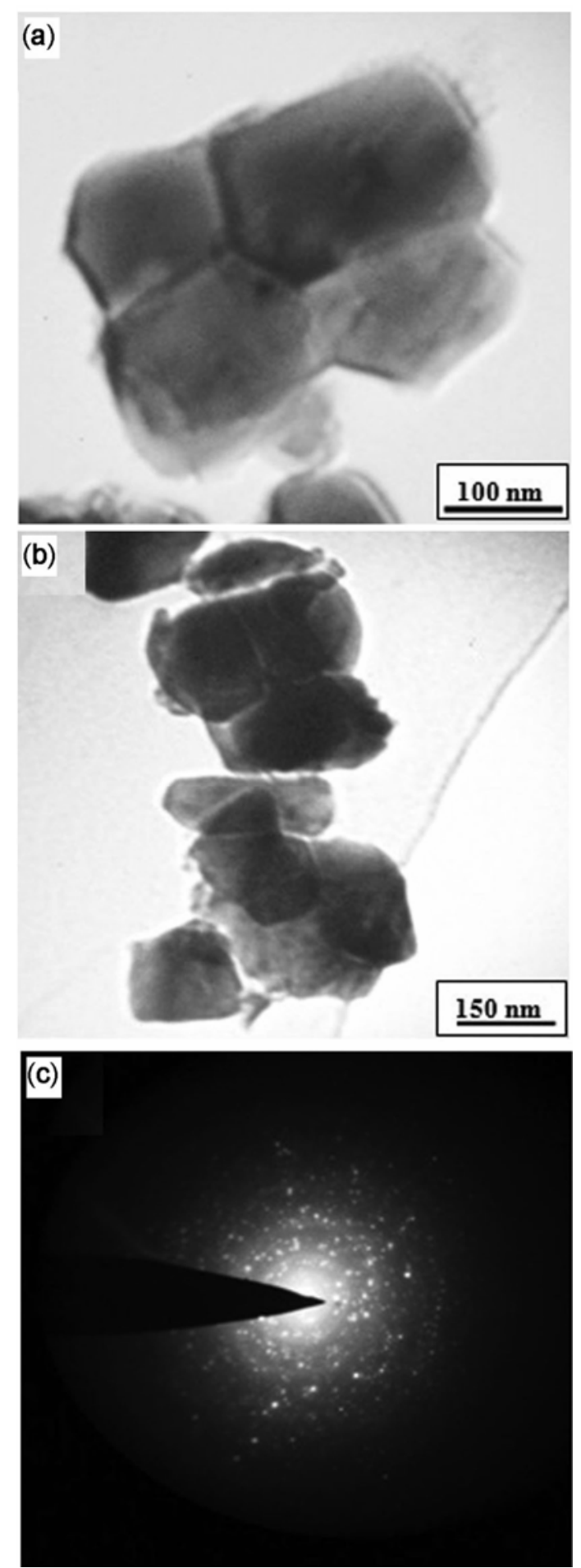

Figure 3. TEM micrographs of the forsterite scaffold. 
Figure 4 shows the XRD pattern of the prepared HA coating. The result shows that at $600^{\circ} \mathrm{C}$, a HA coating was produced with appropriate phase purity and with the crystallite size in the range of $25-29 \mathrm{~nm}$. All the peaks existing in the pattern belong to HA (JCPD 09-0432), which is in good agreement with the research carried out by Hanifi and co-workers. ${ }^{24,25}$

In order to investigate and study the presence of HA coating on the forsterite scaffolds, X-ray map was utilized. Figure 5 shows the X-ray map in the centre of the

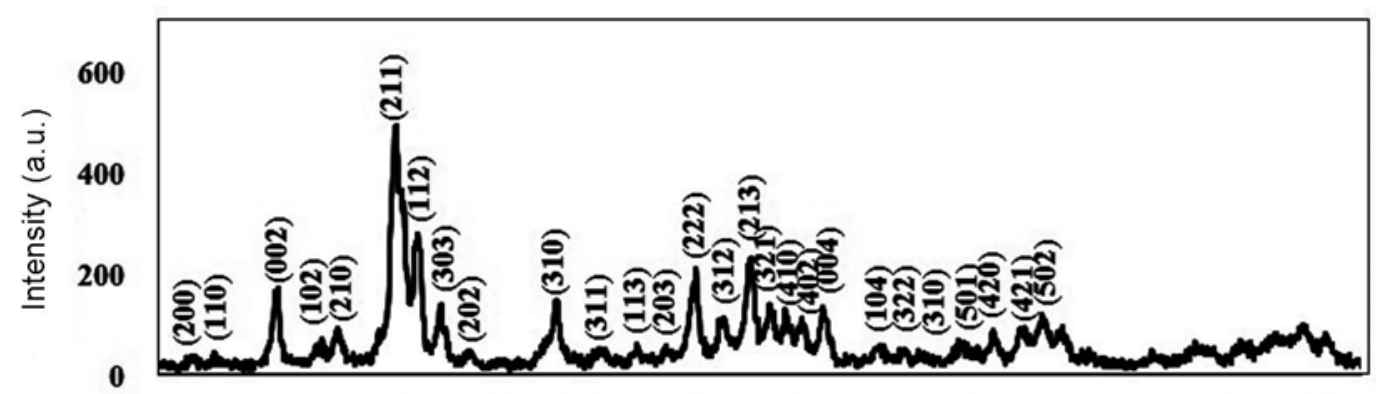

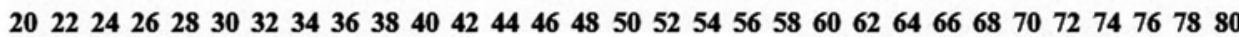
$2 \theta(\mathrm{deg})$

Figure 4. XRD pattern of hydroxyapatite coating.
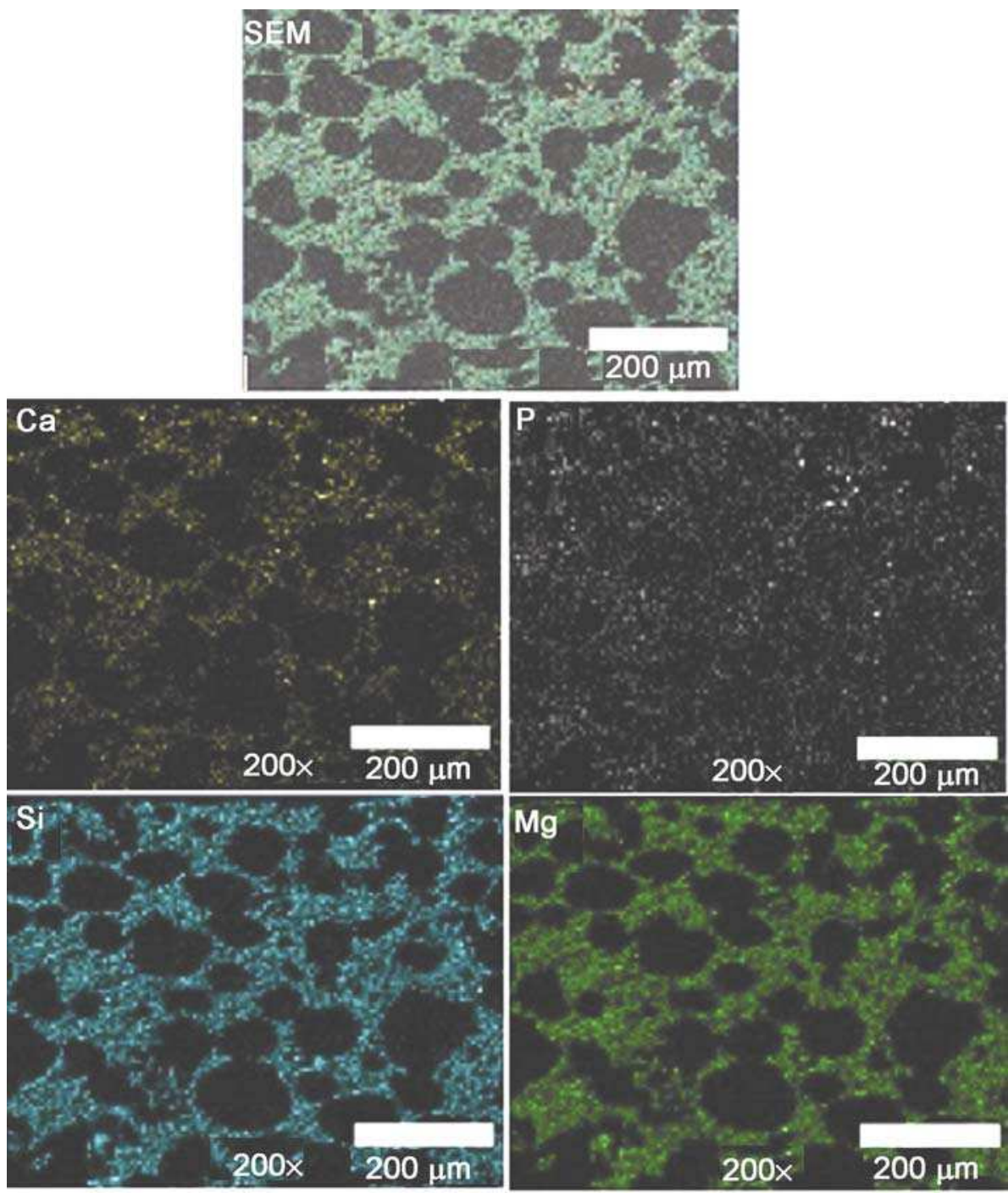

Figure 5. X-ray map of the cross-sectional surface of the hydroxyapatite-coated forsterite scaffold. 
cross-cutting of HA-coated forsterite scaffold. According to figure 5, Ca and $\mathrm{P}$, the main elements of $\mathrm{HA}$, uniformly presented throughout the samples. Demonstrating HA coating could be formed not only on the surface porosities, but also deeply penetrated the samples.

The typical cross-section of the HA-coated forsterite scaffold is shown in figure 6c. As shown in figure 6c, elemental analysis of the inner wall of pore exhibited the presence of calcium and phosphorus, which are the main elements of HA. The thickness of the coating layer was approximately $4 \mu \mathrm{m}$.

The morphology and structure of as-fabricated HAcoated forsterite scaffold are shown in figure 6 . As can be seen from figure 6 , scaffolds had an open, interconnected and uniform porous structure with pore sizes around 65$245 \mu \mathrm{m}$, satisfying the requirements to allow ingrowth of osteoblast cells inside the scaffolds. ${ }^{31}$ Total and open porosity of these scaffolds were in the range of 75-80 and $65-70 \%$, respectively, which were higher than appropriate pores for bone tissue engineering and were in the ranges of the pores in cancellous bone $(50-90 \%){ }^{32}$

A typical compressive stress-strain curve of the HAcoated forsterite scaffolds is shown in figure 7. The scaffolds failed in a manner similar to the brittle bioceramic scaffolds. The elastic modulus and compressive strength of the prepared scaffolds were $291 \pm 10$ and $7.5 \pm 0.2 \mathrm{MPa}$, respectively, which were in the range of compressive strength and elastic modulus of the cancellous bone., ${ }^{4,633}$ Enhanced compressive strength of the HA-coated forsterite scaffold compared to the results of other researchers related to the HA-coated scaffolds ${ }^{12,34,35}$ might be due to the nanostructured forsterite scaffold as substrate. Additionally, compared to Ghomi et al $l^{4}$, research compressive strength of prepared scaffold was increased. There were two reasons for the increase in compressive strength. One was the use of two-step sintering method for preparing nanocrystalline forsterite scaffold, and another was the use of HA coating. Using two-step sintering, forsterite
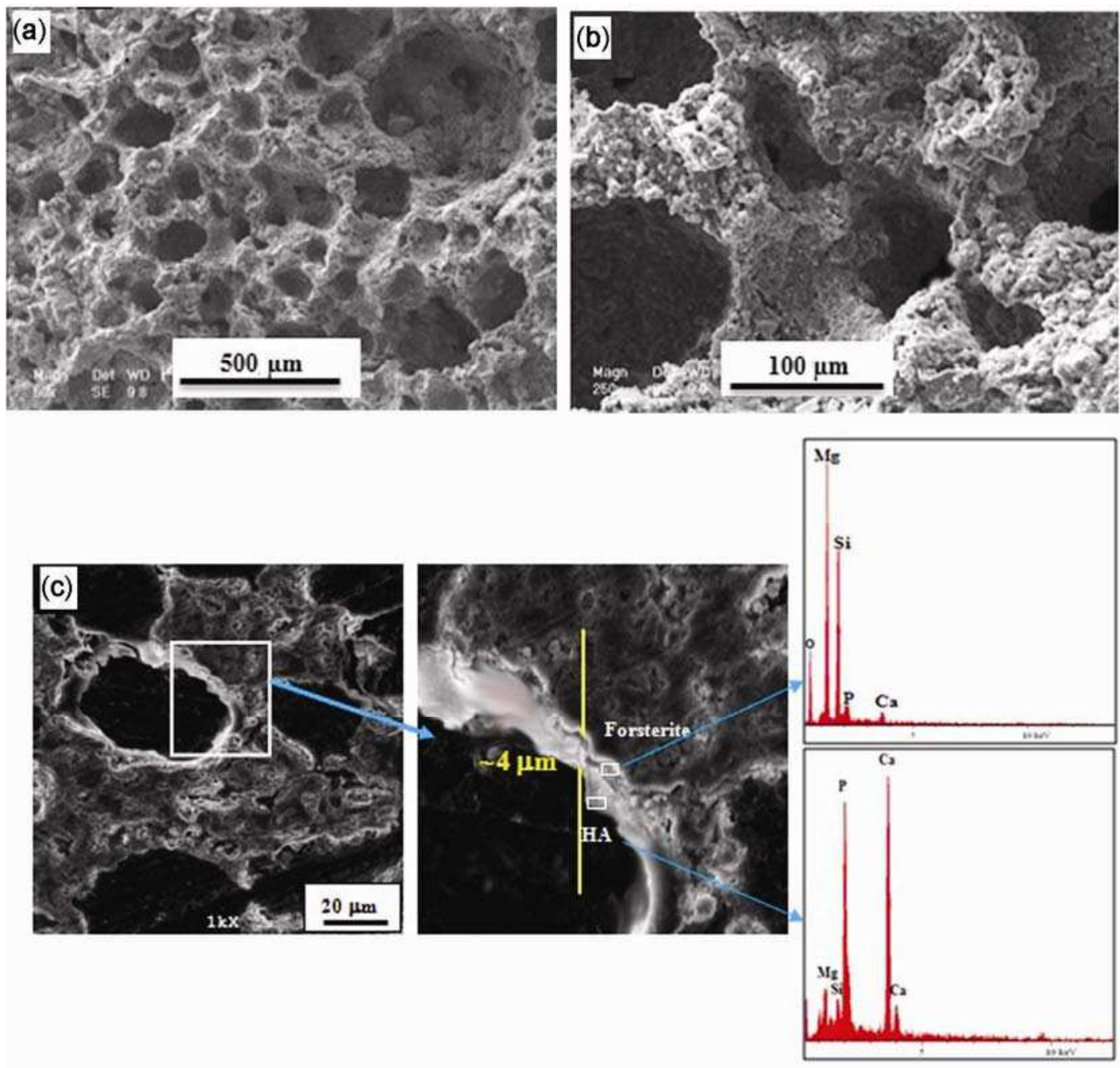

Figure 6. SEM micrographs and EDS pattern of hydroxyapatite-coated forsterite scaffold: (a, b) pore structure and (c) cross-section. 


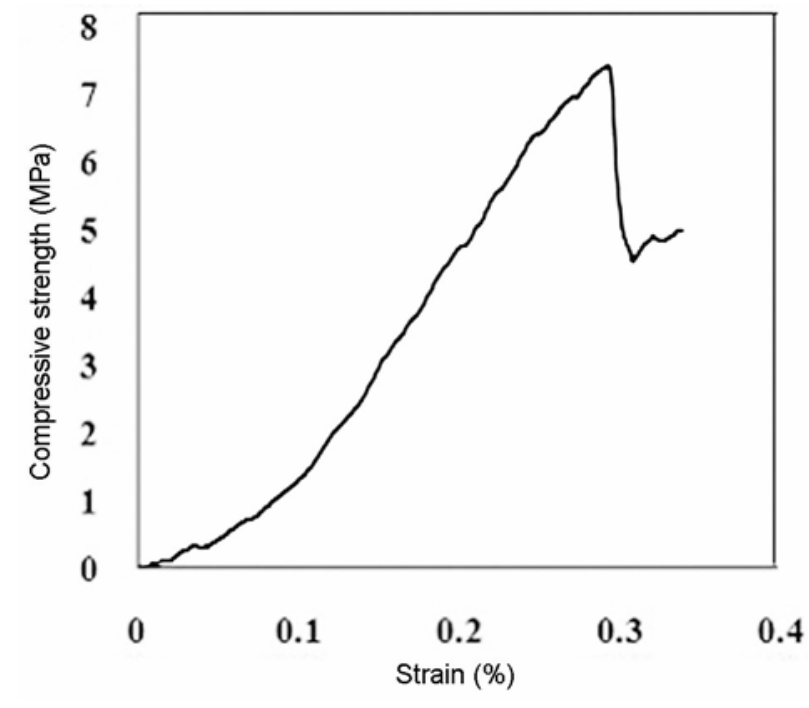

Figure 7. Compressive stress-strain curve of hydroxyapatitecoated forsterite scaffold. scaffold with compressive strength of about $7 \mathrm{MPa}$ and total porosity of about $80 \%$ was produced. By coating forsterite scaffolds with HA, HA-coated forsterite scaffold with compressive strength of about $7.5 \mathrm{MPa}$ and total porosity of about $77 \%$ was produced. Mechanical properties of ceramics are strongly influenced by morphology, porosity and grain size. ${ }^{36,37}$ Although mechanical property of HA is lower than forsterite, ${ }^{13}$ the reason for this increase would be reduction in percentage and size of the porosities. It is well known that a compromise between porosity and mechanical properties exists, where an increase in the void volume and porosity results in a reduction in mechanical strength and stiffness of the scaffold. ${ }^{37,38}$

Figure 8 shows the SEM micrographs of HA-coated forsterite scaffold after soaking in SBF for various periods. The agglomerated bone-like apatite particles could be observed on the surface and inner wall of the pores after 7 days of soaking. By increasing the immersion time, the number and size of these agglomerated
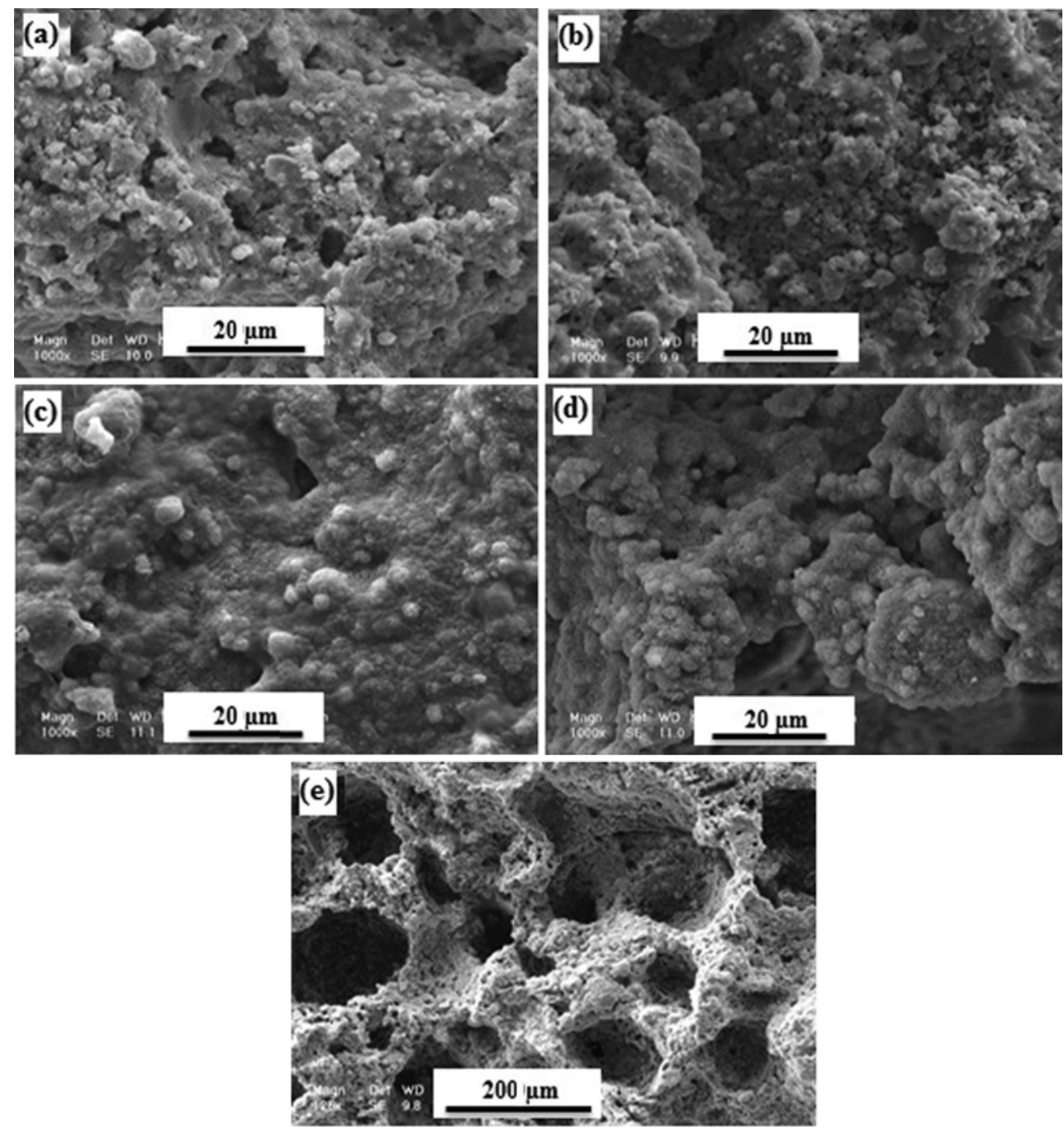

Figure 8. SEM micrographs of hydroxyapatite-coated forsterite scaffold after (a) 7, (b) 14, (c) 21 and (d, e) 28 days of immersion in SBF. 


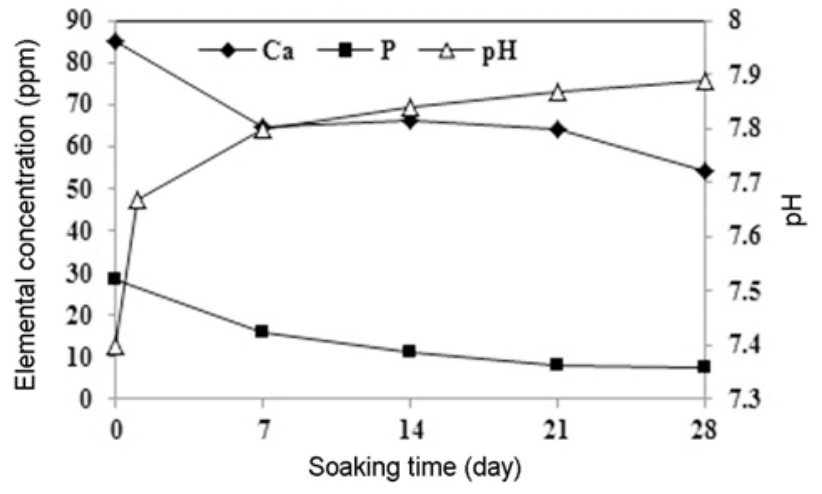

Figure 9. Changes of $\mathrm{Ca}$ and $\mathrm{P}$ concentrations and $\mathrm{pH}$ of the SBF solution after soaking the hydroxyapatite-coated forsterite scaffold for various periods.

particles enhanced, which resulted in a smooth surface at longer immersion time. On the other hand, bone-like apatite formation on the surface changed the morphology and size of the pores of the HA-coated forsterite scaffold.

The graph of $\mathrm{pH}$ changing trend in terms of soaking time is shown in figure 9. It can be seen that increasing the immersion time enhanced the $\mathrm{pH}$ value of SBF from 7.4 to 7.9. When HA-coated forsterite scaffold was immersed in SBF, both HA coating dissolution and deposition of bone-like apatite from the solution were occurred. At the initial stage, the dissolution rate was even slightly higher than the deposition one, resulting in an increase in $\mathrm{pH}$ value in near the surface regions. By increasing the immersion time, the solution near the coating surfaces was supersaturated, and the deposition rate of HA was enhanced. Therefore, after the initial stage, the HA coating was keep growing.

Figure 9 also shows the changes in the $\mathrm{Ca}$ and $\mathrm{P}$ ion concentration of the SBF after soaking the samples in $\mathrm{SBF}$ for various time periods. Reduction in $\mathrm{Ca}$ and $\mathrm{P}$ ion concentrations in SBF was the result of immersion of the samples in SBF.

The use of porous scaffolds for bone regeneration is one of the most common approaches in tissue engineering. Much research has been done on making HA scaffold with desired properties. The scaffolds have already had low mechanical properties. ${ }^{17,34,35}$ Since it is very important to increase the mechanical properties of the porous bioceramics, in the present research, the forsterite scaffold, which has better mechanical properties, was used and was coated with HA. In this case, the mechanical properties of the forsterite and the biocompatibility and bioactivity of the HA can be used simultaneously. Further studies will be focused on cell culture and in vivo tests on the prepared scaffolds.

\section{Conclusion}

Nanostructured forsterite scaffold, with crystallite size of $35-60 \mathrm{~nm}$, was fabricated via the gelcasting method, and was coated with HA by the sol-gel method in low pressure. The crystallite size of the coating was in the range of $25-29 \mathrm{~nm}$. The prepared scaffold had nearly uniform, spherical and interconnected pores, with sizes in the range of $65-245 \mu \mathrm{m}$ and with total and open porosities of about $75-80$ and $65-70 \%$, respectively. The compressive strength and elastic modulus of the prepared scaffold were $7.5 \pm 0.2$ and $291 \pm 10 \mathrm{MPa}$, respectively, which were in the range of the compressive strength and elastic modulus of cancellous bone. The results of immersion samples in SBF proved the good bioactivity of HAcoated nanostructured forsterite scaffold in such a way that at long immersion time, bone-like apatite covered all the surface and inner wall of the scaffold pores. It seems that the collection of good mechanical properties of forsterite and favourable biological properties of HA make the HA-coated forsterite scaffold an appropriate candidate for tissue engineering and load-bearing applications.

\section{Acknowledgement}

We are grateful to Isfahan University of Technology, in particular, the Department of Materials Engineering for supporting this research.

\section{References}

1. Wu C, Chang J, Zhai W, Ni S and Wang J 2006 J. Biomed. Mater. Res. 7847

2. Ni S, Chou L and Chang J 2007 Ceram. Int. 3383

3. Kharaziha M and Fathi M H $2010 \mathrm{~J}$. Mech. Behav. Biomed. Mater. 3530

4. Ghomi H, Jaberzadeh M and Fathi M H 2011 J. Alloys Compd. $\mathbf{5 0 9} 63$

5. Arafa M T, Lam C X F, Ekaputra A K, Wong S Y, Li X and Gibson I 2011 Acta Biomater. 7809

6. Xu H K, Quin J B, Takagi S and Chow L C 2004 Biomaterials 251029

7. Saki M, Narbat M K, Samadikuchaksaraei A, Ghafouri H B and Gorjipour F 2009 Yakhteh Med. J. 1155

8. Wang H, Li Y, Zuo Y, Li J, Ma S and Cheng L 2007 Biomaterials 283338

9. Tripathi G and Basu B 2012 Ceram. Int. 38341

10. Kharaziha M and Fathi M H 2009 Ceram. Int. 352449

11. Tavangarian F and Emadi R 2011 Mater. Lett. 65740

12. Kim H W, Knowles J C and Kim H E 2004 Biomaterials 25 1279

13. Sebdani M M and Fathi M H 2011 Int. J. Appl. Ceram. Technol. 8553

14. Kosanovic C, Stubicar N, Tomasic N, Bermanec V and Stubicard M 2005 J. Alloys Compd. 389306

15. Sasikala T S, Sumab M N, Mohananb P, Pavithran C and Sebastian M T 2008 J. Alloys Compd. 461555

16. Barzegar Bafrooei H, Ebadzadeh T and Majidian H 2014 Ceram. Int. 402869

17. Emadi R, Tavangarian F, Roohani Esfahani S I, Sheikhhosseini A and Kharaziha M $2010 \mathrm{~J}$. Am. Ceram. Soc. 932679 
18. Diba M, Fathi M H and Kharaziha M 2011 Mater. Lett. 65 1931

19. Diba M, Kharaziha M, Fathi M H, Gholipourmalekabadi M and Samadikuchaksaraei A 2012 Compos. Sci. Technol. 72716

20. Fathi M H and Kharaziha M 2008 Int. J. Mod. Phys. B 22 3082

21. Sanosh K P, Balakrishnan A, Francis L and Kima T N 2010 J. Alloys Compd. 495113

22. Tavangarian F and Emadi R 2011 Ceram. Int. 372275

23. Zhang F Z, Kato T, Fuji M and Takahashi M 2006 J. Eur. Ceram. Soc. 26667

24. Fathi M H and Hanifi A 2007 Mater. Lett. 613978

25. Fathi M H, Hanifi A and Mortazavi V 2008 J. Mater. Process. Technol. 202536

26. Fathi M H and Hanifi A 2009 Adv. Appl. Ceram. 108 363

27. Cullity B D 1978 Elements of X-ray diffraction (Windsor Locks, CT, USA: Addison-Wesley)

28. Ji S and Wang Z 1999 Geodynamics 28147
29. Erol M M, Mourino V, Newby P, Chatzistavrou X, Roether J A, Hupa L and Boccaccini A R 2012 Acta Biomater. 8792

30. Bohner $\mathrm{M}$ and Lemaitre J 2009 Biomaterials 302175

31. Bellucci D, Cannillo V and Sola A 2011 Ceram. Int. 37145

32. Fu Q, Saiz E, Rahaman M N and Tomsia A P 2011 Mater. Sci. Eng. 311245

33. Dash S R, Sarkar R and Bhattacharyya S 2015 Ceram. Int. 413775

34. Zhao J, Duan K, Zhang J W, Lu X and Weng J 2010 Appl. Surf. Sci. 2564586

35. Roohani Esfahani S I, NouriKhorasani S, Lu Z, Appleyard $\mathrm{R}$ and Zreiqat $\mathrm{H} 2010$ Biomaterials 315498

36. Padmanabhann S K, Gervaso F, Carrozzo M, Scalera F, Sannino A and Licciulli A 2013 Ceram. Int. 39619

37. Kusmanto F, Walker G, Gan Q, Walsh P, Buchanan F, Dickson G, McCaigue M, Maggs C and Dring M 2008 Chem. Eng. J. 139398

38. Oliveira J M, Silva S, Malafaya P B, Rodrigues M T, Kotobuki N, Hirose M, Gomes M E, Mano J F, Ohgushi H and Reis R L 2009 J. Biomed. Mater. Res. A 91175 